\title{
Heat treatment of glassy carbon implanted with cesium at room and high temperatures
}

\author{
D.F. Langa ${ }^{(a)}$, N.G. van der Berg ${ }^{(a)}$, E. Friedland ${ }^{(a)}$, J.B. Malherbe ${ }^{(a)}$, A.J. Botha ${ }^{(a)}$, \\ P Chakraborty ${ }^{(\mathrm{c})}$, E. Wendler ${ }^{(\mathrm{d})}$, and W. Wesch ${ }^{(\mathrm{d})}$

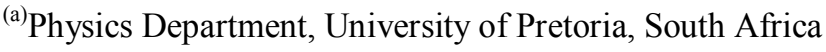 \\ ${ }^{(c)}$ Physics Department, Saha Institute for Nuclear Science, Kolkata, India

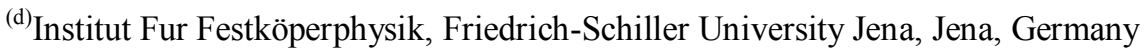

\begin{abstract}
The effects of annealing temperature on the surface morphology and on the diffusion of the cesium implanted into glassy carbon (Sigradur $\left.{ }^{\circledR} G\right)$ are reported. The samples were implanted with $360 \mathrm{keV}$ cesium ions to a fluence of $2 \times 10^{16}$ ions $/ \mathrm{cm}^{2}$ at room temperature, at $350^{\circ} \mathrm{C}$ and at $600^{\circ} \mathrm{C}$. The room temperature implanted samples were isochronally vacuum annealed for 1 hour at temperatures from $200^{\circ} \mathrm{C}$ to $600^{\circ} \mathrm{C}$. The profiles of the implanted samples before and after annealing were obtained by ion beam technique, viz. Rutherford Backscattering Scattering (RBS). Scanning Electron Microscopy (SEM) was employed to investigate the effect of implanted ions and annealing on the microstructure of the substrate.
\end{abstract}

Keywords: Glassy Carbon (SIGRADUR®), RBS, SEM, diffusion, surface topography 


\section{Introduction}

Glassy carbon (GC), also called vitreous carbon, is an advanced material of pure carbon combining glassy and ceramic properties with those of graphite. Unlike graphite, glassy carbon has a fullerene-related microstructure [1]. This leads to a great variety of unique material properties making it a very interesting material with many applications. The structure of glassy carbon has been the subject of research since it was first produced in the early 1960s. Some of the earliest structural models assumed that both $\mathrm{sp}^{2}$ - and $\mathrm{sp}^{3}$-bonded atoms were present [2]. Glassy carbon is a particularly interesting form of disordered carbon. Micro-structurally, it consists of a tangle of graphite like ribbons or micro-fibrils. These fibers are of the order of $100 \AA$ long and 30 $\AA$ wide [3].

In the present work we investigate the changes in the microstructure of the glassy surface after heat treatment of glassy carbon implanted with $360 \mathrm{keV}$ Cs ions to a fluence of $2 \times 10^{16}$ $\mathrm{Cs}^{+} / \mathrm{cm}^{2}$ at room and high temperatures. In many applications, the knowledge on impurity atoms diffusion is of crucial importance, hence the implanted glassy carbon samples were also isochronally annealed to investigate the transport of the implanted Cs in the glassy carbon.

\section{Experimental Method}

The glassy carbon (GC) samples as the substrate were mechanically polished to a mirror finish with a $1 \mu \mathrm{m}$ diamond solution and cleaned consecutively with alkaline soap, de-ionized water, acetone, and methanol and dried with nitrogen gas. Finally, the samples were placed in an oven at $80^{\circ} \mathrm{C}$ about 30 minute to evaporate volatile impurities on the surface. Cesium was implanted into the polished surface, at energy of $360 \mathrm{keV}$, to a fluence of $2 \times 10^{16} \mathrm{Cs}^{+} / \mathrm{cm}^{2}$. The 
flux was maintained at a rate of about $10^{13} \mathrm{~cm}^{-2} \mathrm{~s}^{-1}$ to minimize the increase in the substrate temperature, reducing the probability of simultaneously annealing some of the radiation damage produced during the room temperature implantations. The implantations were done at three different substrate temperatures, viz. room temperature $(\mathrm{RT}), 350^{\circ} \mathrm{C}$ and $600^{\circ} \mathrm{C}$. The room temperature implanted samples were vacuum annealed isochronally in a quartz tube furnace for 1 hour at temperatures from $200^{\circ} \mathrm{C}$ up to $600^{\circ} \mathrm{C}$. A thermocouple placed near the sample's position is connected to a computer to record the temperature as a function of time during annealing. The concentration distributions of $\mathrm{Cs}$ in GC samples before and after annealing were determined using Rutherford Backscattering Scattering (RBS) at room temperature using $\alpha$-particles with energy of 1.6 MeV. An Ultra ZEISS 55 field emission gun Scanning Electron Microscopy (SEM) was employed to study the samples surface to investigating the effect of implantation and annealing temperature on the microstructure of the substrate.

\section{Results and discussion}

The RBS spectra of glassy carbon as-implanted with $360 \mathrm{keV}$ cesium ions at a fluence of 2 $\times 10^{16} \mathrm{Cs}^{+} / \mathrm{cm}^{2}$ at $\mathrm{RT}, 350^{\circ} \mathrm{C}$ and $600^{\circ} \mathrm{C}$ are shown in Fig. 1 . The profile for implantation at room temperature shows that there is a diffusion of the implanted Cs towards the surface. This outdiffusion of the Cs is enhanced at the two higher implantation temperatures with a distinct Cs surface peak being formed at the $600^{\circ} \mathrm{C}$ sample. This is due to the substrate temperature effect and radiation induced diffusion. The amount of $\mathrm{Cs}$ on the surface, for the $600^{\circ} \mathrm{C}$ implanted sample, is $5.46 \times 10^{14} \mathrm{Cs}^{+} / \mathrm{cm}^{2}$ which is less than a monolayer. This indicates that $\mathrm{Cs}$ segregates to the surface. The RBS spectra show that although there is also some diffusion of the Cs into the bulk of the glassy carbon, it is very little and does not extend deep into the bulk. This together 


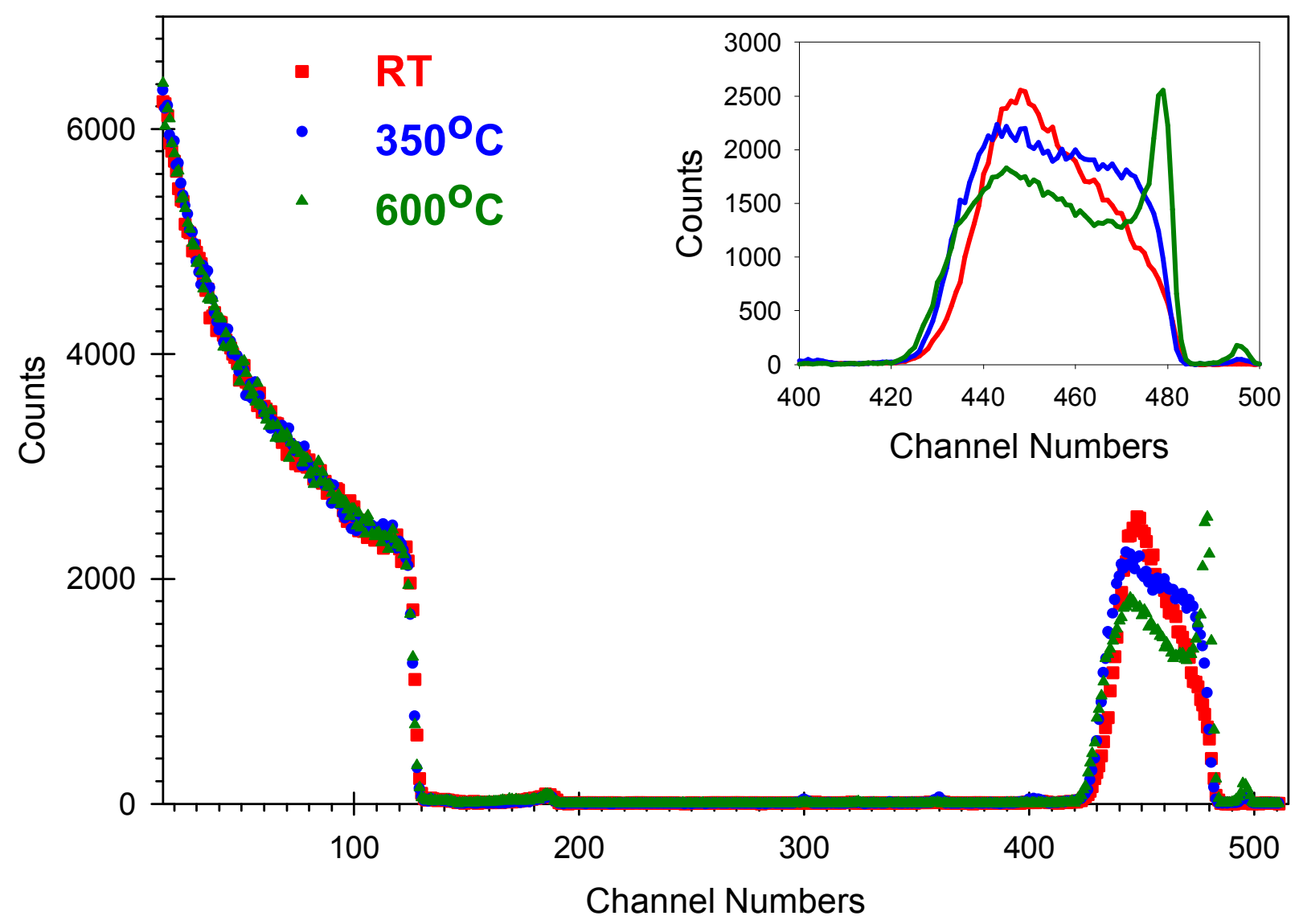

Fig. 1. Glassy carbon implanted with $360 \mathrm{keV}$ cesium ions at a fluence of $2 \times 10^{16} \mathrm{Cs}^{+} / \mathrm{cm}^{2}$ at $\mathrm{RT}(\square), 350^{\circ} \mathrm{C}(\bullet)$ and $600^{\circ} \mathrm{C}(\boldsymbol{\Delta})$.

with the diffusion/segregation towards the surface indicates that this diffusion is induced by the radiation damage in the glassy carbon. Due to knock-on effects and the Gaussian shape of the implanted ion distribution, the radiation-induced damage extends slightly beyond the implantation profiles observed by RBS, thereby allowing some of the implanted Cs to diffuse into this damaged region.

Fig. 2 shows the energy spectra of backscattered ${ }^{4} \mathrm{He}$ ions for GC samples implanted with $360 \mathrm{keV} \mathrm{Cs}^{+}$at room temperature. The maximum Cs concentration of approximately 60 at. $\%$ is 


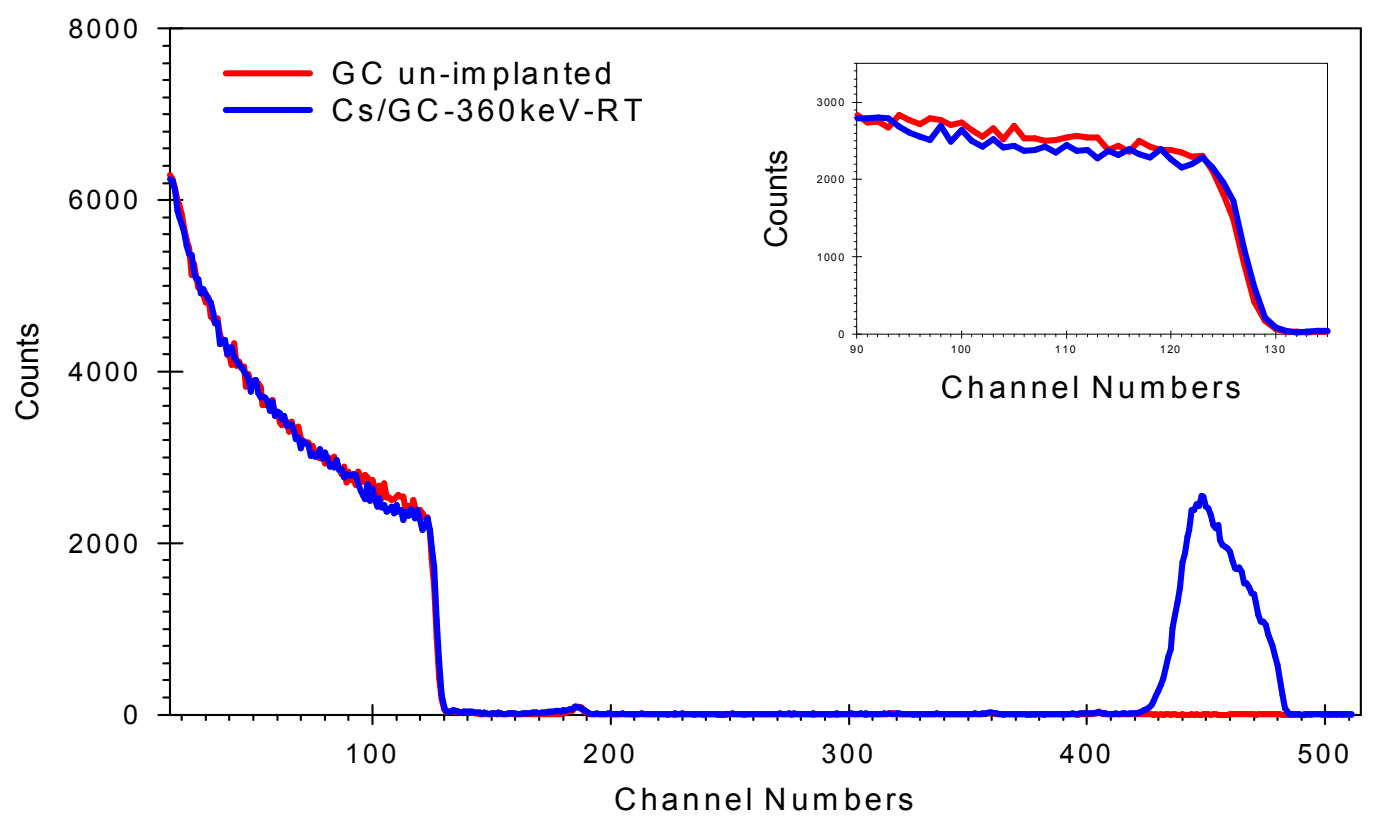

Fig. 2. RBS spectra of GC un-implanted $(-)$ and implanted $(-)$ with $360 \mathrm{keV}$ cesium ions at a fluence of $2 \times 10^{16} \mathrm{Cs}^{+} / \mathrm{cm}^{2}$ at RT.

directly evaluated from the peak height. The implantation of Cs atoms leads to the decrease in the backscattering yields of carbon atoms at a depth corresponding to the projected range of Cs ions (see inset of Fig. 2). The depression between channels 93 and 126 is due to the presence of Cs atoms implanted. The SRIM [4] calculated and measured room temperature implanted Cs depth profiles are shown in Fig. 3. Excellent agreement between the calculated projected range of 206 $\mathrm{nm}$ and the depth at maximum Cs of the measured profiles of $216 \mathrm{~nm}$, may be observed. The Skewness (0.1766) and Kurtosis (2.9125) of the calculated Cs ion range profile illustrate that it is Gaussian. On the other hand, the experimental profile is not symmetric.

To determine whether the radiation-induced diffusion observed in Figure 1 is purely a substrate temperature effect, we isochronally annealed the sample implanted at room temperature 


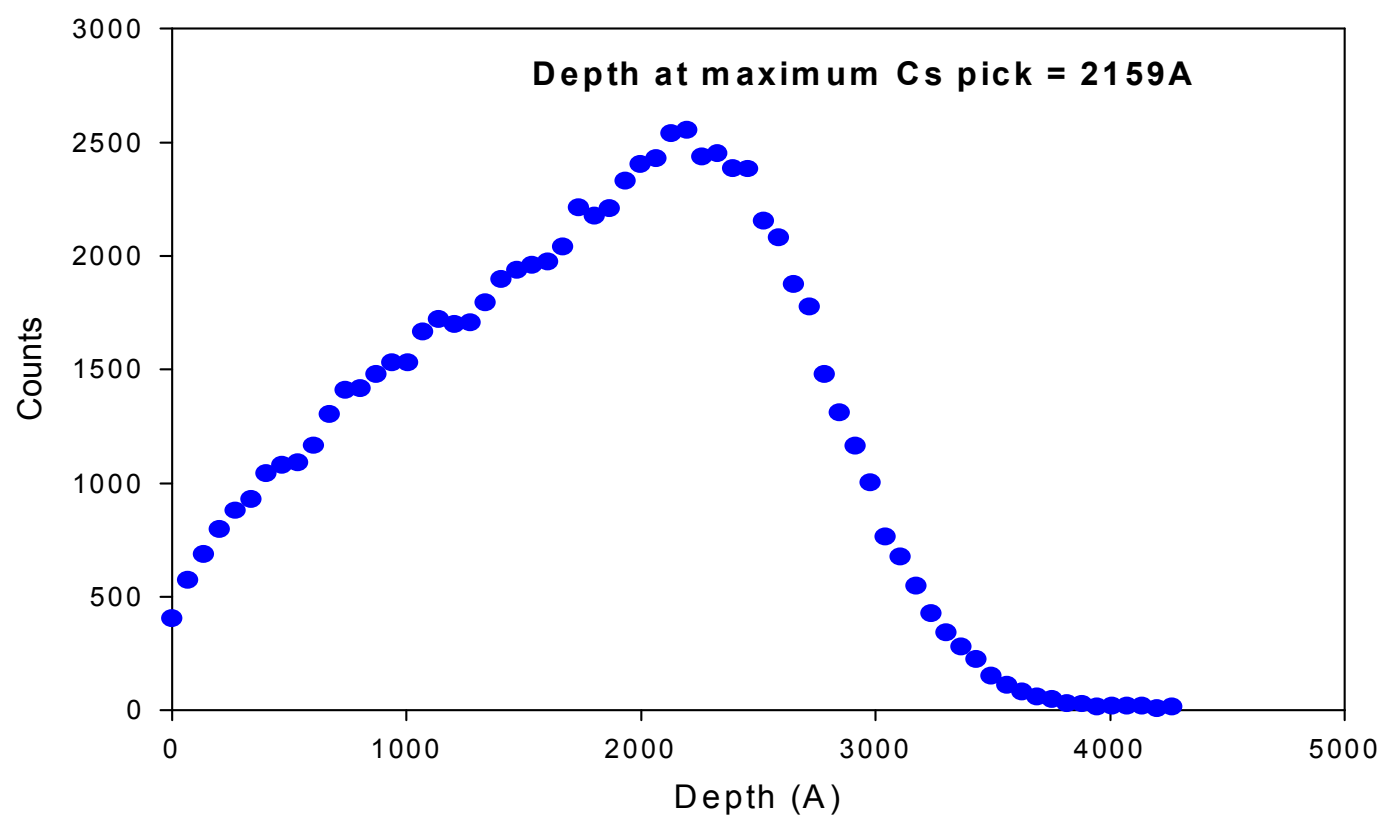

(a)

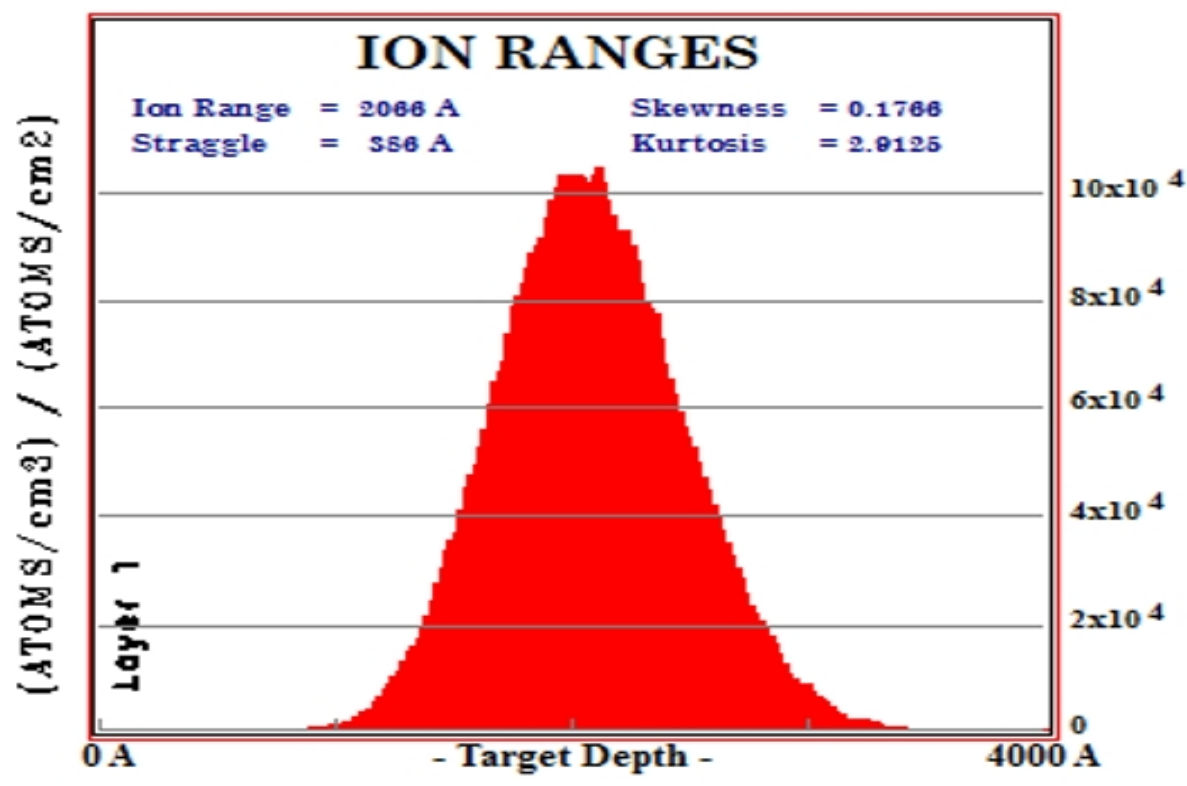

(b)

Fig. 3. Projected range of $360 \mathrm{keV} \mathrm{C}$ at a fluence of $2 \times 10^{16} \mathrm{Cs}^{+} / \mathrm{cm}^{2}$ implanted into GC at RT. (a) Experimental depth profile, and (b) SRIM calculation.

for 1 hour at temperature ranges from $200^{\circ} \mathrm{C}$ to $600^{\circ} \mathrm{C}$. It must be born in mind that it is expected 
that the room temperature implanted glassy carbon would have significantly higher radiation damage than the samples implanted at elevated temperature samples because self-annealing usually takes place during high temperature implantations [5]. The RBS spectra of these samples (see Figure 4) showed some significant differences with those depicted in Figure 1. In Fig. 1, Cs diffuses towards the surface and remains on the surface. By comparing the areas under the Cs peaks we found that only $0.7 \%$ of the implanted Cs was lost during $350^{\circ} \mathrm{C}$ and $2.9 \%$ during the $600^{\circ} \mathrm{C}$ implantations. In contrast, the room temperature implanted and then annealed samples lost significant Cs. The results are summarized in Table 1. The out-diffusion profile shapes were

Table 1. Percentages of cesium lost from GC implanted with $360 \mathrm{keV}$ cesium ions to a fluence of $2 \times 10^{16} \mathrm{Cs}^{+} / \mathrm{cm}^{2}$ at RT, then isochronally annealed for 1 hour at $200^{\circ} \mathrm{C}, 300^{\circ} \mathrm{C}, 400^{\circ} \mathrm{C}, 500^{\circ} \mathrm{Cand}$ $600^{\circ} \mathrm{C}$.

\begin{tabular}{|c|c|}
\hline Annealing Temperatures & Cesium lost \\
\hline $200^{\circ} \mathrm{C}$ & $4 \%$ \\
\hline $300^{\circ} \mathrm{C}$ & $1 \%$ \\
\hline $400^{\circ} \mathrm{C}$ & $6 \%$ \\
\hline $500^{\circ} \mathrm{C}$ & $29 \%$ \\
\hline $600^{\circ} \mathrm{C}$ & $72 \%$ \\
\hline
\end{tabular}

also different. The Cs profiles of the isochronal annealed samples were consistent with an out diffusion of Cs to the surface and a subsequent sublimation/evaporation of the Cs into the 
vacuum. This sublimation/evaporation of the Cs into the vacuum was due to the low melting point of $29^{\circ} \mathrm{C}$ of Cs. The out-diffusion is naturally temperature dependent with more diffusion at the higher temperature resulting in the lowering of the concentration of the Cs depth profiles at the higher annealing temperatures. Also observed from Fig. 4, there was also a Cs profile changes on the bulk side of the glassy carbon as the samples are annealed. This profile changes illustrate small amounts of Cs in-diffusion due to annealing. For the temperatures of $300^{\circ} \mathrm{C}-600^{\circ} \mathrm{C}$, the depth through which the Cs diffuse into glassy carbon is the same again suggesting that the initial ion bombardment induced radiation damage plays a significant role in this in-diffusion. There was a significant difference between the room temperature implanted sample after annealing for $1 \mathrm{~h}$ at $600^{\circ} \mathrm{C}$ and the sample implanted with the substrate being at $600^{\circ} \mathrm{C}$. In the latter case the implantation time was about $30 \mathrm{~min}$., i.e. shorter but comparable with the $1 \mathrm{~h}$ annealing of the former. The surprising and interesting aspect of this study was the sticking of the Cs to the glassy carbon surfaces during implantation at the elevated temperatures. This suggests that the implantation process caused the formation of some meta-sfie compound between the Cs and carbon substrate atoms. This meta-stable compound catches the Cs in the matrix not allowing the Cs to escape into the vacuum.

Fig. 5 (a)-(d) is the SEM images of glassy carbon surfaces before and after implantation, and after annealing the room temperature implanted sample. The glassy carbon surface before Cs implantation shows polishing marks, though not prominent, which are due to mechanical polishing. These polishing effects change with implantation conditions and annealing. After implantation they were much more visible as observed in Fig. 5 (b) and (c), and this was due to sputtering of loosely bounded carbon atoms to expose the scratches. As for the room temperature implantation it was observed that these polishing effect are more prominent than at higher 


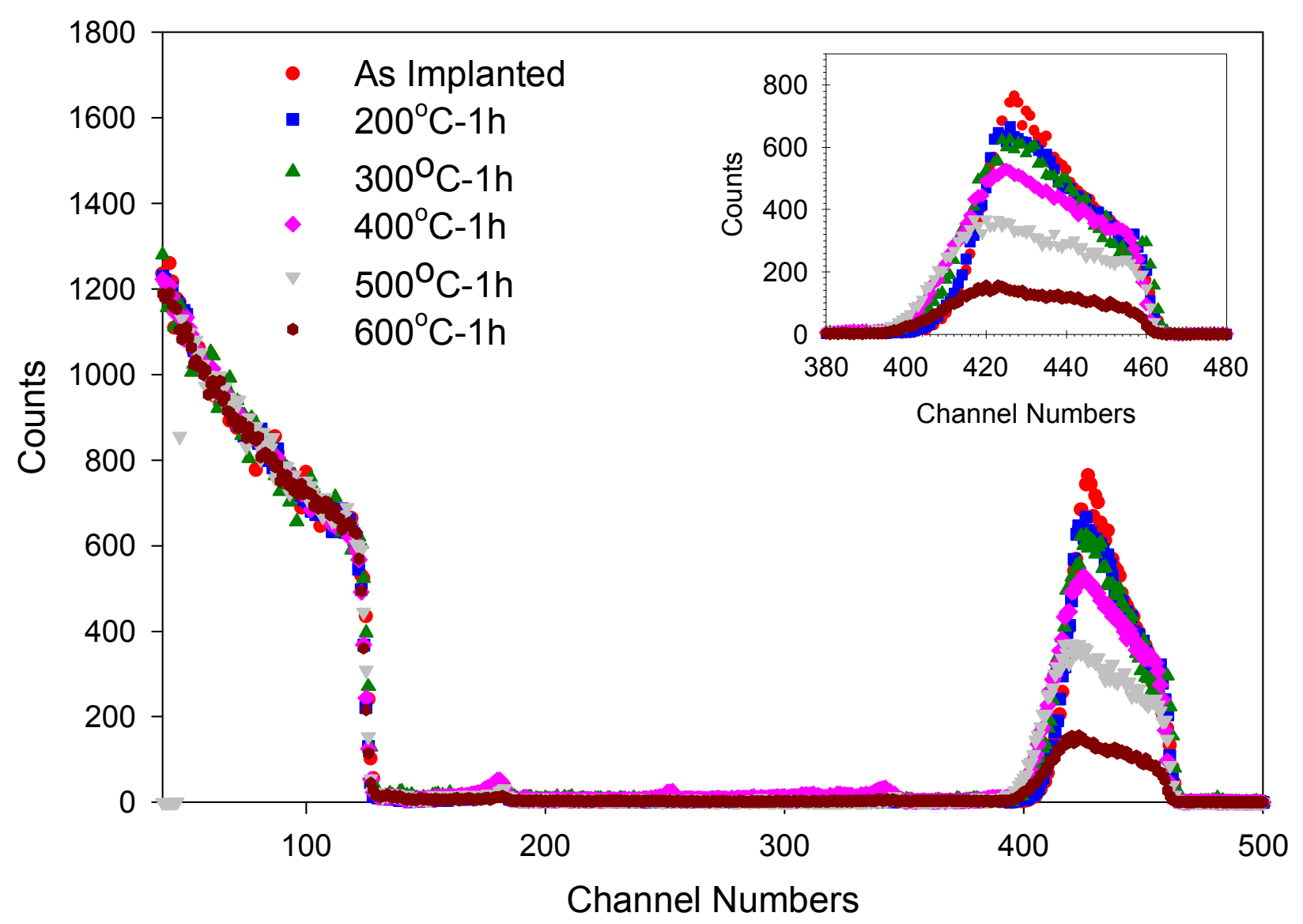

Fig. 4. GC implanted with $360 \mathrm{keV}$ cesium ions at a fluence of $2 \times 10^{16} \mathrm{Cs}^{+} / \mathrm{cm}^{2}$ at RT, then isochronally annealed for 1 hour at $200^{\circ} \mathrm{C}, 300^{\circ} \mathrm{C}, 400^{\circ} \mathrm{C}, 500^{\circ} \mathrm{C}$ and $600^{\circ} \mathrm{C}$.

temperature implantations. The difference was considered to be due to the segregated Cs atoms observed on the surface, as illustrated in the backscattering profiles of Fig.1, cover the polishing scratches. Annealing the glassy carbon implanted with $360 \mathrm{keV} \mathrm{Cs}^{+}$ions revealed the polishing effect more and many micro-pores can be clearly seen, which were not observed on the high temperature implanted glassy carbon samples. The sponge like structure inside the micro-pores could be clearly seen in Fig. 5(d). Similar results were observed after glassy carbon irradiation with $100 \mathrm{keV} \mathrm{N}_{2}{ }^{+}$to a dose of $4 \times 10^{17} \mathrm{~N}^{+} / \mathrm{cm}^{2}[6]$. 

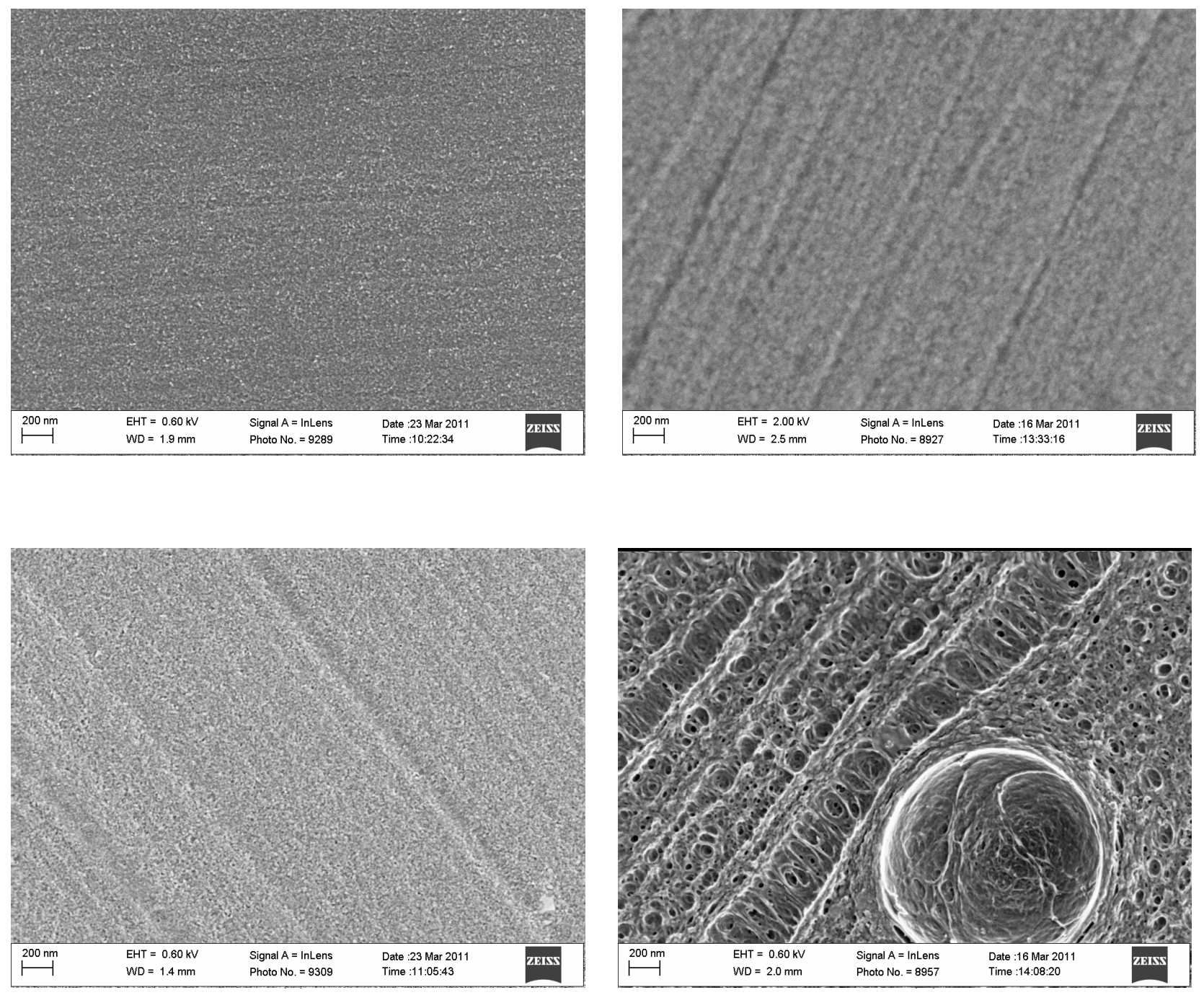

Fig. 5. SEM images of GC (a) polished surface, implanted with $360 \mathrm{keV}$ cesium ions at a fluence of $2 \times 10^{16} \mathrm{Cs}^{+} / \mathrm{cm}^{2}$ at (b) RT and (c) $600^{\circ} \mathrm{C}$, then (d) annealed at $200^{\circ} \mathrm{C}$ for 8 hours.

It has previously been reported that the surface of glassy carbon has spots which become hollows after irradiation with $1 \times 10^{18} \mathrm{Ne}^{+} / \mathrm{cm}^{2}$, the removed material being deposited nearby [6-7]. We also observed a similar formation of holes on glassy carbon which was only lightly mechanically polished and then irradiated with $2 \times 10^{16} \mathrm{Ag}^{+} / \mathrm{cm}^{2}$ [8]. In the present samples a much thicker layer was removed by mechanical polishing steps. These surfaces showed no holes 
after irradiation with $2 \times 10^{16} \mathrm{Cs}^{+} / \mathrm{cm}^{2}$. This illustrated that the observed spots and the appearance of holes during irradiation was the property of the top layers of the glassy carbon which could be a manufacturing effect.

\section{Conclusion}

Cs-ion implantation into glassy carbon was performed at $360 \mathrm{keV}$ to a fluence of $2 \times 10^{16} \mathrm{Cs}^{+} / \mathrm{cm}^{2}$ at room temperature, $350^{\circ} \mathrm{C}$ and $600^{\circ} \mathrm{C}$. It was observed that there is a diffusion of the implanted Cs towards the surface even at room temperature and is enhanced at higher implantation temperatures. This out diffusion, whereby Cs segregates to the surface, was due to the substrate temperature effect and radiation induced damage. The Cs diffusion out sticks to the glassy carbon surfaces during implantation at elevated temperatures. This was suggested to be due to the formation of some meta-stable compound between Cs and carbon substrate atoms, catching up the Cs not to escape into the vacuum. There was excellent agreement between the SRIM calculated projected range of $206 \mathrm{~nm}$ and the depth at maximum Cs on the measured profile of $216 \mathrm{~nm}$ for the room temperature Cs implanted depth. Annealing of the room temperature implanted samples, shows increasing amounts of Cs loss as the annealing temperature increase, and a subsequent sublimation/evaporate into the vacuum. Micro-pores with sponge like structures inside could clearly be seen on room temperature glassy carbon surface after annealing at just $200^{\circ} \mathrm{C}$ for 8 hours. This was not observed on the glassy carbon surfaces implanted at elevated temperatures. 


\section{Acknowledgements}

Financial support of the National Research Foundation and the BundesministeriumfürBildung und Forschung is gratefully acknowledged. Thanks are due to Gerald Lenk for implantation and Ulrich Barth for RBS measurements, both from the InstitutfürFestkörperphysik, FriedrichSchiller-Universität Jena, for the implantation

\section{References}

[1] P.J.F. Harris. Phil. Mag., 84, 29 (2004) 3159-3167

[2] G.M. Jenkins, K. Kawamura, L.L. Ban, Proc. Roy. Soc., A 82 (1972) 501

[3] G.M. Jenkins and K. Kawamura, Polymeric Carbons-carbon Fibre, Glass and Char, Cambridge University Press, London, 1976

[4] J.F. Ziegler, SRIM 2010 computer code, www.srim.org

[5] E Friedland, N.G. van der Berg, J.J. Malherbe, E Wendler, W Wesch, Submitted to J. Nucl. Materials (2011)

[6] Y. Kazumata, J. Nuclear Materials 71 (1977) $178-180$

[7] K Takahiro, R Ookawa, K Kawatsura, F Nishiyama, S Nagata, S Yamamoto, K Narumi, H Naramoto, M Iwaki, Nucl. Instr. And Meth. B 2006 (2008) 206 - 210

[8] D.F. Langa, N.G. van der Berg, E. Friedland, J.B. Malherbe, A.J. Botha, W. Wesch, E. Wendler, and P Chakraborty, To be published. 